\title{
On the representation of timing for different structures within MRP theory
}

\author{
Marija Bogataj and Robert W Grubbström
}

\section{Linköping University Post Print}

N.B.: When citing this work, cite the original article.

Original Publication:

Marija Bogataj and Robert W Grubbström, On the representation of timing for different structures within MRP theory, 2012, International Journal of Production Economics, (140), 2, 749-755.

http://dx.doi.org/10.1016/j.ijpe.2011.04.016

Copyright: Elsevier

http://www.elsevier.com/

Postprint available at: Linköping University Electronic Press

http://urn.kb.se/resolve?urn=urn:nbn:se:liu:diva-86646 


\title{
On the Representation of Timing for Different Structures within MRP Theory
}

\author{
Marija Bogataj ${ }^{\dagger}$ and Robert W. Grubbström FVR RI ${ }^{\ddagger}$ \\ ${ }^{\dagger}$ Faculty of Economics, University of Ljubljana, Kardeljeva Ploscad 17, SI-1000 Ljubljana, Slovenia \\ ${ }^{\ddagger}$ Linköping Institute of Technology, SE-581 83 Linköping, Sweden \\ * Mediterranean Institute for Advanced Studies, SI-5290 Šempeter pri Gorici, Slovenia \\ Email: †marija.bogataj@guest.arnes.si,
}

\begin{abstract}
MRP Theory has been developed during the last 25 years for capturing processes concerning multi-level, multistage production-inventory systems in a compact way. Input-.Output Analysis has been used to describe structures, and Laplace transforms to describe the timing relations. This theory has mainly dealt with assembly systems, in which each item has only one successor. The lead times for the assembly of an item have usually been constants and equal for all items entering a given successor. For such systems, the equations describing the flows of components may be written to include the generalised input matrix as the product of an input matrix containing needed amounts, and a diagonal lead time matrix with lead time operators along its main diagonal.

On occasion, there has been a need to deviate from this representation enabling lead times to vary depending on which input item that is considered. This paper deals with how to represent lead times and similar output delays (in diverging, arborescent systems), when the assumption of equal times is relaxed, in order to retain the basic structure of the fundamental balance equations involved. The intention of this paper is to create a general taxonomy for the representation of timing in algebraic form for a variety of systems covering both assembly systems and arborescent systems (such as extraction, distribution and remanufacturing), as well as systems with mixed properties. For instance, this method may be used directly for the evaluation of investments in capacity or in the location of activities in a production network, or even in a global supply chain.
\end{abstract}

Keywords: MRP theory, transportation, distribution, location, lead times, Laplace transform, input-output analysis, multi-stage production-inventory systems.

\section{Importance of Timing Considerations in Production and Supply Systems}

The timing of activities in a production inventory system or a supply chain often depends on the location of production or distribution units (activity cells), which belong to the chain, and the accessibility and other properties of these units play an important role. Optimal decisions (i) where to produce, (ii) how much to produce, (iii) how often to produce, (iv) how to distribute the product and (v) when to order or deliver items in integrated production and supply system can be successfully analysed and evaluated in a transformed environment, where lead times and other time delays can be considered as linear operators.

An example is the site and capacity selection problem, concerning where it is best to locate a facility and what capacity is needed to achieve a most rapid response. This issue is discussed more easily in the transformed environment. Lead times in the entire supply chain can be analysed in compact form using Material Requirements Planning (MRP) [Orlicky 1975] combined with Input-Output Analysis, cf. [Leontief 1928, 1951] in a Laplace transformed space. Orlicky used tabular forms for entering the requirements at the advanced lead time. In [Grubbström and Ovrin 1992] the authors presented the first application of transforms for the same purpose, using the z-transform for discrete time lead times, in later papers to be 
exchanged for the Laplace transform for continuous time lead times, cf. [Grubbström and Tang 2000].

We can consider the activities of the integrated supply chain as having four distinct subsystems: (i) manufacturing, (ii) physical distribution (iii) consumption and (iv) remanufacturing. All four sub-systems can be defined in the time domain, or in the frequency domain.

These four parts and the flows of goods in between them are illustrated in Figure 1.

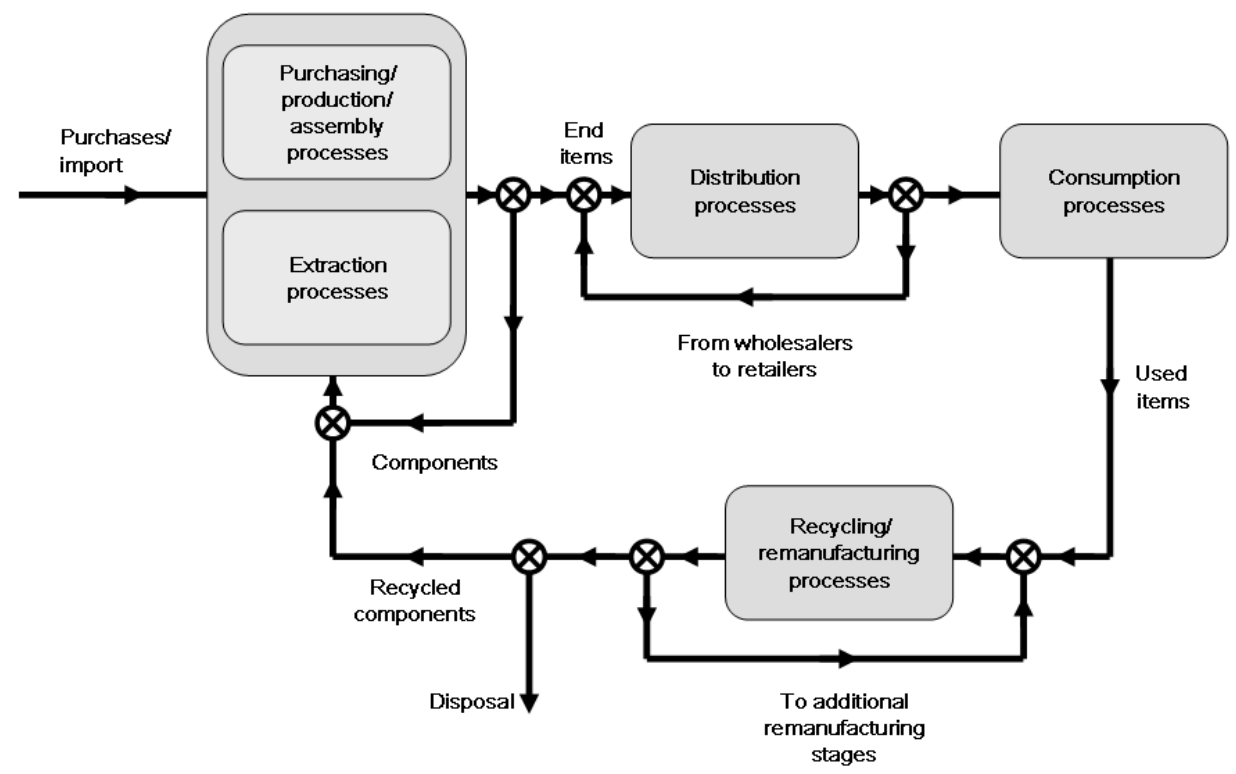

Figure 1. The integrated production and supply system with vector valued flows of good, from [Grubbström, Bogataj and Bogataj 2007].

In the units of the manufacturing part, lead times are essential ingredients, and in the distribution part transportation times are important. The lead time of a process is the time in advance of completion that the requirements are requested. Such lead times in practice and theory are most often assumed to be the same for all input components entering an assembly process. But the time delay can also be substantial because of transportation between two different locations. Then there is a need to relax the assumption of identical lead times for all components, and allow for a generalisation of the theory to include a variety of possible advanced timing requirements. This was recognised by M. Bogataj [1999], but not further elaborated in a general form. Similarly, for a distribution system, the time to reach a destination will be different for the same product produced in different units. Also here, a relaxation of a constant time assumption is called upon. Analogous observations may be made concerning the remanufacturing sub-system.

This type of generalisation is the topic of the current paper.

This study allows applications with all parts of the integrated supply chain: Manufacturing, physical distribution, consumption and remanufacturing. For instance, this method may be used directly for the evaluation of investments in capacity or in the location of activities in a production network, or even in a global supply chain . 
According to the authors' knowledge this is the first time that the general representation of different lead-times and output delays in MRP theory is introduced in detail and their impact on the Net Present Value (NPV) consequences of activities in a distribution chain is evaluated. The NPV principle has been a natural way of expressing the economic consequences in MRP Theory, since cash flows written as transforms are immediately evaluated as to their NPV by exchanging the Laplace frequency for the continuous interest rate following the NPV Theorem of the Laplace Transform [Grubbström 1967].

For those who are not acquainted with MRP theory, the basics are given in Section 2. A further generalisation of this theory to Assembly and Arborescent Systems is developed in Section 3. A numerical example also illustrating an application of NPV methodology is introduced in Section 4, followed by a conclusions section added at the end of this generalisation.

Readers who are not acquainted with basic MRP theory are kindly invited to read the earlier article "An Overview of Input-Output Analysis Applied to Production-Inventory Systems" [Grubbström and Tang, 2000].

We wish to stress that the treatment in this paper is focused on developing a theoretical extension of MRP Theory, rather than on investigating and furthering additional solution methodology, the latter being dealt with in other research, such as in [Grubbström, Bogataj and Bogataj, 2009, Grubbström and Tang, 2011]. Various heuristic approaches to model and solve related problems, mainly for assembly systems, have been developed by different authors, such as simulated annealing and genetic algorithms [Kuik and Salomon 1990, Kim and Kim 1996, Kimms 1999, Dellaert and Jeunet 2000, Delleart et al. 2000, Tang 2004, Kaku et al. 2009].

\section{Basic analysis}

In the linear production-economic models belonging to Input-Output Analysis (or Activity Analysis) there are two main classes of objects, (i) products (items), and (ii) processes. Items flow into and out of processes [Koopmans 1951, Lancaster 1968, Grubbström 1997, Ch. 3]. Often, in graphical form, processes are represented by vertices (nodes) and flows by directed arcs (edges). The processes transform the input flows into output flows of new products.

In the following a function of time $f(t), t \geq 0$, is assumed to have a unique Laplace transform written as $£\{f(t)\}$ or $\tilde{f}(s)$ and defined by

$$
\tilde{f}(s)=£\{f(t)\}=\int_{t=0}^{\infty} f(t) e^{-s t} d t
$$

where $s$ is the Laplace frequency (complex frequency), and the integral is assumed to exist [Aseltine 1958]. The inverse transform translating the function from the frequency domain to the time domain is written $\mathcal{E}^{-1}\{\tilde{f}(s)\}=f(t)$. Normally we need never bother about the complex nature of this variable. For reasons of limited space, we understand in the following that the reader is familiar with MRP Theory in which Input-Output Analysis and Laplace transforms are combined in their use for analysing Material Requirements Planning (MRP) systems, cf. for instance [Grubbström 1996, Grubbström and Tang 2000, Grubbström 2007, 2009, Grubbström, Bogataj and Bogataj 2009]. 
The basic relationship between flows and processes belonging to the linear theory is, on the one hand the proportionality between the input flows and an input vector describing the process, where the activity level is a coefficient of proportionality, and, on the other, a proportionality between the output flows and an output vector, where the coefficient of proportionality is the same activity level. Activity levels are often interpreted as decision variables.

The input and output vectors contain non-negative constants as components. If the number of all existing types of products $n$ defines the dimension of the input and output vectors, and $y_{j}$ is the activity level the process numbered $j$, then the input flow will be $y_{j} \mathbf{h}_{j}$ and the output flow $y_{j} \mathbf{g}_{j}$, where $\mathbf{h}_{j}$ is the input- and $\mathbf{g}_{j}$ the output vector of the process.

A linear production system is made up of a set of processes. Let the number of processes be $m$. Listing the $m$ input vectors side by side defines the input matrix $\mathbf{H}$ of the system, and, similarly, listing the output vectors side by side forms the output matrix $\mathbf{G}$ of the system. These matrices will then have the dimension of $n \times m$. Arranging the activity levels into a vector $\mathbf{y}$, the system as a whole will have total input flows of $\mathbf{H y}$ and total output flows of $\mathbf{G y}$. The difference between $\mathbf{G y}$ and $\mathbf{H y}$ may be interpreted as net production $\mathbf{z}$ :

$$
\mathbf{z}=(\mathbf{G}-\mathbf{H}) \mathbf{y}=\sum_{j=1}^{m} y_{j}\left(\mathbf{g}_{j}-\mathbf{h}_{j}\right) .
$$

A positive component of $\mathbf{z}$ indicates an opportunity to export this surplus from the system, and a negative component a need to import this quantity. The matrix $\mathbf{H}$ may be interpreted as an adjacency matrix belonging to the graph representing the flows, cf. [Rosen 1988, pp. $369 \mathrm{ff}$.

When each process delivers its own type of product and introducing purchasing processes for products not produced by the system, we have an elementary system, and each process may be given the same index as the product that it delivers. The matrices $\mathbf{G}$ and $\mathbf{H}$ must then be square, and $m=n$. Furthermore, if a unit activity level is then interpreted as a state when the output flow is unity, the output matrix becomes the identity matrix I. Net production is then $\mathbf{z}=(\mathbf{I}-\mathbf{H}) \mathbf{y}$, where $\mathbf{y}$ is both the vector of activities and the vector of total output flows from production, so total production will be given by

$$
\mathbf{y}=(\mathbf{I}-\mathbf{H})^{-1} \mathbf{z},
$$

provided that the inverse $(\mathbf{I}-\mathbf{H})^{-1}$, the Leontief inverse, exists.

Assembly systems, studied by Andrew Vazsonyi, belong to the category of elementary systems. Each assembly is a process with an inflow of one or several other products (items). The products on the lowest level in the product structure have no inputs and must be imported to the system, whereas top-level items can be exported. By suitable enumeration, so that a higher-level product in the structure has a lower index, the input matrix $\mathbf{H}$ becomes triangular as recognised by Vazsonyi [1955, 1958]. The technology matrix $(\mathbf{I}-\mathbf{H})$ then has a unitvalued determinant guaranteeing the Leontief inverse to exist. In graphical form the input matrix (the "next assembly quantity matrix" and the Leontief inverse named as the "total 
requirement factor matrix" in the terminology of Vazsonyi), may be represented by a Gozinto Graph. The product structure tree is an alternative graphical representation (cf. Figure 2).

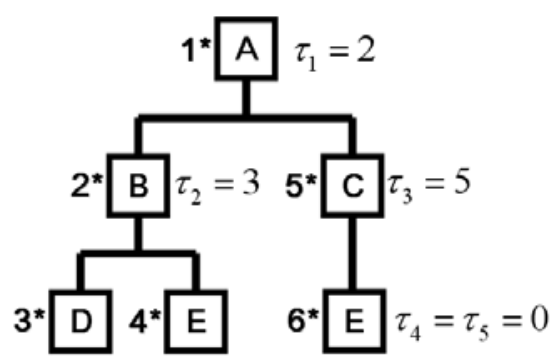

(i)

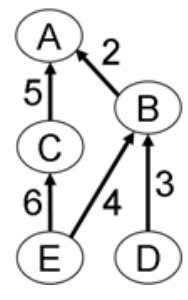

(ii)

$$
\mathbf{H}=\left[\begin{array}{lllll}
0 & 0 & 0 & 0 & 0 \\
2 & 0 & 0 & 0 & 0 \\
5 & 0 & 0 & 0 & 0 \\
0 & 3 & 0 & 0 & 0 \\
0 & 4 & 6 & 0 & 0
\end{array}\right]
$$

(iii)
$(\mathbf{I}-\mathbf{H})^{-1}=\left[\begin{array}{ccccc}1 & 0 & 0 & 0 & 0 \\ 2 & 1 & 0 & 0 & 0 \\ 5 & 0 & 1 & 0 & 0 \\ 6 & 3 & 0 & 1 & 0 \\ 38 & 4 & 6 & 0 & 1\end{array}\right]$

(iv)

Figure 2. Example of the Assembly System: (i) Product structure tree with lead times shown, (ii) Gozinto Graph, (iii) Input matrix, (iv) Leontief inverse.

When studying MRP (Material Requirements Planning) systems, the items for assembly are needed a certain time in advance of the completion time of the process. This is the lead time. For a certain process, say process $j$, the lead time of all input components is assumed to be the same, so the lead time of this process $\tau_{j}$ becomes a constant property of the process. In MRP Theory, we interpret the activity vector $\mathbf{y}$ as a production vector $\mathbf{P}$. Using Laplace transform methodology, if a component of $\mathbf{P}$, say $P_{j}$, represents the output of the process $j$ at a certain time, then all inputs for this assembly will be required at a time given by $P_{j} e^{s \tau_{j}} \mathbf{h}_{j}$, where $e^{s \tau_{j}}$ is an operator defining the advanced timing of the inputs as compared to the completion (output) for this particular process. Further, by letting $\tilde{\mathbf{P}}(s)$ denote the transform of $\mathbf{P}$ (as a function of time), and collecting the operators into a diagonal matrix $\tilde{\boldsymbol{\tau}}(s)$, the amounts and times of required inputs will be $\mathbf{H} \tilde{\boldsymbol{\tau}}(s) \tilde{\mathbf{P}}(s)$ and net production to be exported (the Master Production Schedule) will be

$$
\tilde{\mathbf{D}}(s)=(\mathbf{I}-\mathbf{H} \tilde{\boldsymbol{\tau}}(s)) \tilde{\mathbf{P}}(s),
$$

all in terms of transforms, which is to be compared with (2). The net production is thus readily interpreted as the external demand vector $\tilde{\mathbf{D}}(s)$. This leads to the general Lot-For-Lot formula (L4L) in MRP Theory, cf. [Grubbström, Bogataj and Bogataj 2009],

$$
\tilde{\mathbf{P}}(s)=(\mathbf{I}-\mathbf{H} \tilde{\boldsymbol{\tau}}(s))^{-1} \tilde{\mathbf{D}}(s),
$$

which is valid for any assembly type system and any set of lead times. This formula explains how production should be sized and timed for any situation with given production structures $\mathbf{H}$ and lead times (included in $\tilde{\boldsymbol{\tau}}(s)$ ), and a Master Production Schedule $\tilde{\mathbf{D}}(s)$. when applying the L4L lotsizing principle.

We now turn to an opposite system to the assembly system, namely an arborescent system (cf. Figure 3). In such a system each input has one or several outputs, so the output matrix $\mathbf{G}$ becomes triangular, whereas the input matrix takes the form of the identity matrix $\mathbf{I}$. 


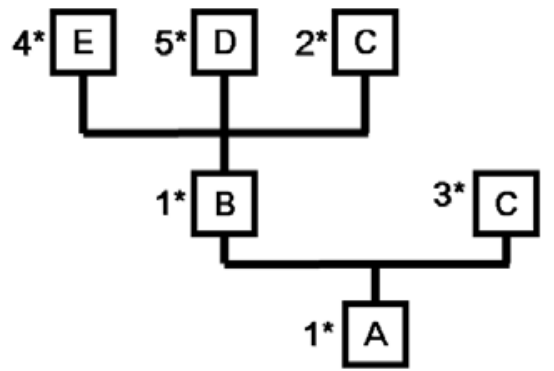

(i)

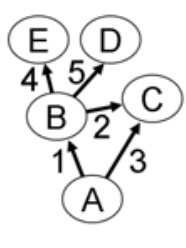

(ii)

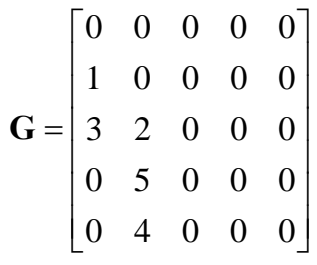

(iii)
$(\mathbf{G}-\mathbf{I})^{-1}=-\left[\begin{array}{ccccc}1 & 0 & 0 & 0 & 0 \\ 1 & 1 & 0 & 0 & 0 \\ 5 & 2 & 1 & 0 & 0 \\ 5 & 5 & 0 & 1 & 0 \\ 4 & 4 & 0 & 0 & 1\end{array}\right]$

(iv)

Figure 3. Example of the Pure Arborescent System: (i) Product structure tree, (ii) "Comezoutof" Graph, (iii) Output matrix,

(iv) Technology matrix inverse (with all elements non-positive).

Considering a certain process $j$, the timing of outputs would be expected to differ depending on their type, an example being a disassembly. So we can attach an output delay time $\Delta_{i j}$ to each product $i$ leaving process $j$. The output of type $i$ from process $j$ having the activity level $P_{j}$, will then be sized and timed according to $P_{j} e^{-s \Delta_{i j}} g_{i j}$. If all products of a certain kind $i$, have the same delay, we can drop the second index $j$, and write the delay as $\Delta_{i}$. Then the outputs from the process will be $P_{j} e^{-s \Delta_{i}} g_{i j}$ and the output as a whole from the system may be written $\tilde{\Delta}(s) \mathbf{G} \tilde{\mathbf{P}}(s)$, where $\tilde{\Delta}(s)$ is a diagonal matrix collecting the operators $e^{-s \Delta_{i}}$. Hence, the net output in total from a system of arborescent processes will be:

$$
\tilde{\mathbf{D}}(s)=(\tilde{\boldsymbol{\Delta}}(s) \mathbf{G}-\mathbf{I}) \tilde{\mathbf{P}}(s) .
$$

This type of system, extending the production part of the supply chain to distribution has first been mentioned in [Bogataj and Bogataj 2003] and then later investigated in detail in [Grubbström, Bogataj and Bogataj 2007, Grubbström 2009].

The above developments lead to conjecture possible extensions, by which net production would be written in a general form as

$$
\tilde{\mathbf{D}}(s)=\left(\tilde{\boldsymbol{\Delta}}(s) \mathbf{G} \tilde{\boldsymbol{\Delta}}^{\prime}(s)-\tilde{\boldsymbol{\tau}}^{\prime}(s) \mathbf{H} \tilde{\boldsymbol{\tau}}(s)\right) \tilde{\mathbf{P}}(s),
$$

where $\tilde{\Delta}^{\prime}(s)$ and $\tilde{\boldsymbol{\tau}}^{\prime}(s)$ are two new diagonal matrices, the former with timing as a property of each process and the latter in which timing is a property of each product. The elements in $\tilde{\boldsymbol{\Delta}}^{\prime}(s)$ would cover delays for outputs which have the same incremental magnitude for each process, and elements in $\tilde{\boldsymbol{\tau}}^{\prime}(s)$ would cover advanced timing for inputs, which have the same incremental magnitude for each product. This slight generalisation retains the multiplicative structure of the generalised technology matrix.

Obviously when $\tilde{\boldsymbol{\Delta}}(s), \tilde{\boldsymbol{\Delta}}^{\prime}(s)$ and $\tilde{\boldsymbol{\tau}}^{\prime}(s)$ are identity matrices (all $\Delta_{i}, \Delta_{i}^{\prime}$ and $\tau_{i}^{\prime}$ are zero), we have timing according to a standard MRP system, and when $\tilde{\Delta}^{\prime}(s), \tilde{\boldsymbol{\tau}}^{\prime}(s)$ and $\tilde{\boldsymbol{\tau}}(s)$ are identity matrices (all $\Delta_{i}^{\prime}, \tau_{i}^{\prime}$ and $\tau_{i}$ are zero), we cover the system purely with arborescent processes and timing attached to each product. 
For a disassembly system, which is an instant of an arborescent system, the mirror image of Vazonyi’s Gozinto Graph may be called a “Comezoutof Graph” [Grubbström 2008, 2009], cf Figure 2. In [Ferrer and Whybark 2000] was recognised the opportunity to model disassembly processes using output matrices.

In order to understand details of what the generalisations in (7) incorporate, we investigate the contribution from one activity component of $\tilde{\mathbf{P}}(s)$, say $\tilde{P}_{j}(s)$, to the net production $\tilde{\mathbf{D}}(s)$, its ith component $\tilde{D}_{i}(s)$ taking the value:

$$
\tilde{D}_{i}(s)=\sum_{j=1}^{m}\left(e^{s\left(\Delta_{j}^{\prime}-\Delta_{i}\right)} g_{i j}-e^{s\left(\tau_{j}-\tau_{i}^{\prime}\right)} h_{i j}\right) \tilde{P}_{j}(s) .
$$

Apparently, the formula (7) covers cases when an output entry in $\mathbf{G}$ may be moved in time relative to a reference time by a difference $\left(\Delta_{j}^{\prime}-\Delta_{i}\right)$ between a property of the process and a property of the product, and, similarly, an input entry in $\mathbf{H}$ moved a difference in time $\left(\tau_{j}-\tau_{i}^{\prime}\right)$ between a second property of the process and of the product.

It has been recognised by [Bogataj 1999, Bogataj, and Bogataj 2003, Bogataj and Bogataj 2001, Bogataj, Grubbström, and Bogataj 2009] that this generalisation is not enough to incorporate processes when the output delay time differs between processes, and other processes by which the lead time is not the same for all input products, and especially where delay is exposed to risk [Bogataj and Bogataj 2007]. For such cases, in particular for transportation, the latter often belonging to the class of arborescent (diverging flow) systems, we attempt to provide a further generalisation which is developed in the succeeding section.

\section{A Further Generalisation to Assembly and Arborescent Systems}

Reverting to the assembly system, we consider the case in which the time in advance at which components are needed is $\tau_{i j}$, which is not necessarily equal for all pairs of $(i, j)$. For such a system the components $i$ have to be available at time $\left(t-\tau_{i j}\right)$, with $t$ being the reference time. Instead of requirements being sized and timed as

$$
\mathbf{H} \tilde{\boldsymbol{\tau}}(s) \tilde{\mathbf{P}}(s)=\left[\begin{array}{cccc}
0 & 0 & \cdots & 0 \\
h_{21} & 0 & \cdots & 0 \\
\vdots & \vdots & \ddots & \vdots \\
h_{n 1} & h_{n 2} & \cdots & h_{n m}
\end{array}\right]\left[\begin{array}{ccc}
e^{s \tau_{1}} & \cdots & 0 \\
\vdots & \ddots & \vdots \\
0 & \cdots & e^{s \tau_{m}}
\end{array}\right] \tilde{\mathbf{P}}(s)=\tilde{\mathbf{H}}(s) \tilde{\mathbf{P}}(s)
$$

where $\tilde{\mathbf{H}}(s)$ is the generalised input matrix $\tilde{\mathbf{H}}(s)=\mathbf{H} \tilde{\boldsymbol{\tau}}(s)$, we may write the requirements as

$$
\left[\begin{array}{cccc}
0 & 0 & \cdots & 0 \\
h_{21} e^{s \tau_{21}} & 0 & \cdots & 0 \\
\vdots & \vdots & \ddots & \vdots \\
h_{n 1} e^{s \tau_{n 1}} & h_{n 2} e^{s \tau_{n 2}} & \cdots & 0
\end{array}\right] \tilde{\mathbf{P}}(s)=\breve{\mathbf{H}}(s) \tilde{\mathbf{P}}(s)
$$


where $\breve{\mathbf{H}}(s)$ is a further generalisation of the input matrix, and where $\breve{\mathbf{H}}(s)$ provides the opportunity for prolonged or shorter lead times for certain products compared to the mandate of $\tilde{\mathbf{H}}(s)$, a diversification that $\tilde{\mathbf{H}}(s)$ does not allow.

As an antisymmetric case, we consider introducing the opportunity for each process in an arborescent system to have output delays $\Delta_{i j}$ which might be given as different for the same product as an output from different processes. From above, when the system does not own this opportunity, the outputs are given as

$$
\tilde{\mathbf{G}}(s) \tilde{\mathbf{P}}(s)=\tilde{\boldsymbol{\Delta}}(s) \mathbf{G} \tilde{\mathbf{P}}(s)=\left[\begin{array}{cccc}
0 & 0 & \cdots & 0 \\
g_{21} e^{-s \Delta_{2}} & 0 & \cdots & 0 \\
\vdots & \vdots & \ddots & \vdots \\
g_{n 1} e^{-s \Delta_{n}} & g_{n 2} e^{-s \Delta_{n}} & \cdots & 0
\end{array}\right] \tilde{\mathbf{P}}(s),
$$

where $\tilde{\mathbf{G}}(s)$ is the generalised output matrix. By now introducing this further flexibility, we may write the outputs as

$$
\left[\begin{array}{cccc}
0 & 0 & \cdots & 0 \\
g_{21} e^{-s \Delta_{21}} & 0 & \cdots & 0 \\
\vdots & \vdots & \ddots & \vdots \\
g_{n 1} e^{-s \Delta_{n 1}} & g_{n 2} e^{-s \Delta_{n 2}} & \cdots & 0
\end{array}\right] \tilde{\mathbf{P}}(s)=\breve{\mathbf{G}}(s) \tilde{\mathbf{P}}(s)
$$

where, in general, the output matrix $\breve{\mathbf{G}}(s)$ no longer is possible to write as the product of a diagonal output delay matrix and the original output matrix $\mathbf{G}$ only containing quantities but no timing. But we are still able to keep a multiplicative separation between the decision variables contained in $\tilde{\mathbf{P}}(s)$ and the given system properties contained in $\breve{\mathbf{H}}(s)$ and/or $\breve{\mathbf{G}}(s)$, respectively.

It should be clear that our previous equations (4) and (6) are special cases of our new generalisations, i.e. when all $\tau_{i j}=\tau_{j}$ are equal for different values of their first index, and when all $\Delta_{i j}=\Delta_{i}$ are equal for different values of their second index.

Nothing prevents us now from stating the equations pertaining to a general mixed system containing assembly as well as arborescent processes, and even processes that themselves simultaneously have more than one input and more than one output. The net production of such a system can then conveniently be written:

$$
\tilde{\mathbf{D}}(s)=(\breve{\mathbf{G}}(s)-\breve{\mathbf{H}}(s)) \tilde{\mathbf{P}}(s) .
$$

In standard literature, $\mathbf{G}-\mathbf{H}$ is called the technology matrix, and in MRP Theory $\tilde{\mathbf{G}}(s)-\tilde{\mathbf{H}}(s)$ has been named the generalised technology matrix, so $\breve{\mathbf{G}}(s)-\breve{\mathbf{H}}(s)$ represents a further generalisation of the technology matrix. 
Let $\tilde{\mathbf{F}}(s)$ be the vector of deliveries from the system. These are normally exports satisfying external demand $\tilde{\mathbf{D}}(s)$, but they may also be surplus items requiring disposal. Then, given a plan $\tilde{\mathbf{P}}(s)$, available inventory of all products as a vector $\tilde{\mathbf{R}}(s)$ will develop according to

$$
\tilde{\mathbf{R}}(s)=\frac{\mathbf{R}(0)+(\breve{\mathbf{G}}(s)-\breve{\mathbf{H}}(s)) \tilde{\mathbf{P}}(s)-\tilde{\mathbf{F}}(s)}{s},
$$

where $\mathbf{R}(0)$ collects initial available inventory levels. The division by $s$ represents a time integration of the flows represented by the other terms. The term $\breve{\mathbf{G}}(s) \tilde{\mathbf{P}}(s)$ is the inflow into available inventory of purchasing, production, extraction, distribution etc., the term $\breve{\mathbf{H}}(s) \tilde{\mathbf{P}}(s)$ is the required outflow representing needs generated by all processes (internal demand, dependent demand) and the term $\tilde{\mathbf{F}}(s)$ represents deliveries (exports) from the system.

Equation (14) is an instance of a generalisation of the fundamental equations of MRP theory. In order for the plan $\tilde{\mathbf{P}}(s)$ to be feasible, we must always have Laplace inverse of available inventories nonnegative: $£^{-1}\{\tilde{\mathbf{R}}(s)\} \geq \mathbf{0}$. This is the available inventory constraint. If also capacity limitations are considered, a corresponding set of constraints for available capacities should be possible to be formulated also in this generalised case, cf. [Segerstedt 1996, Huynh 2006, Grubbström and Wang 2000, 2003].

\section{A Numerical Example}

In this section we provide a numerical example of the case of an assembly system, to which assumptions about transportation times differing between different inputs are added. We depart from a product structure as depicted in Figure 4.

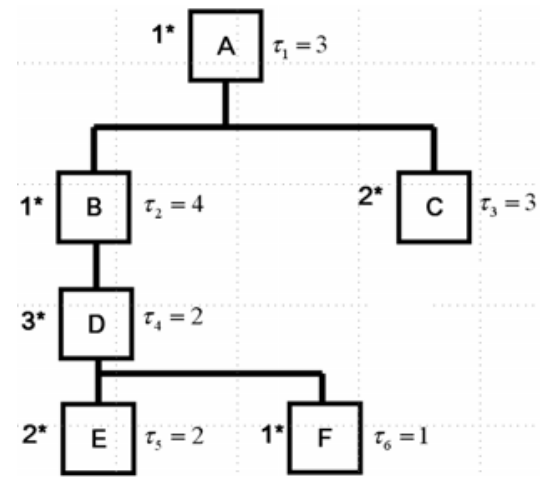

Figure 4. Example of a traditional supply chain structure of an assembly type.

According to Figure 4, there are six activities and products (items). Activity D represents the assembly of 2 units of item $E$ and 1 unit of item $F$, activity $B$ requires 3 units of $D$ for the production of one unit of $B$, and at the top level activity $A$ demands 1 unit of $B$ and 2 units of $C$ for producing one unit of the end product $A$.

Transportation times in this example are shown in the left part of Table 1, and the production lead times being the same for all inputs are shown in the bottom row. As an example, item $D$ entering $B$ is required to be available 4 time units in advance of the completion of $B$, but transportation to $B$ adds another 2 time units when $D$ is to be ordered. This results in a value 
of $\tau_{42}=\tau_{\mathrm{DB}}=6$, and the operator multiplying the element $h_{42}=h_{\mathrm{DB}}$ will be $e^{6 s}$. The resulting individual lead times for each element in $\breve{\mathbf{H}}(s)$ are shown in the right part of Table 1.

\begin{tabular}{|c|c|c|c|c|c|c||c|c|c|c|c|c|}
\hline & \multicolumn{5}{|c||}{ Transportation lead time } & \multicolumn{7}{|c|}{ Time entries for operators in $\breve{\mathbf{H}}(s)$} \\
\hline From/to & $A$ & $B$ & $C$ & $D$ & $E$ & $F$ & $A$ & $B$ & $C$ & $D$ & $E$ & $F$ \\
\hline$A$ & & & & & & & 3 & 4 & 3 & 2 & 2 & 1 \\
\hline$B$ & 4 & & & & & & 7 & 4 & 3 & 2 & 2 & 1 \\
\hline$C$ & 3 & & & & & & 6 & 4 & 3 & 2 & 2 & 1 \\
\hline$D$ & & 2 & & & & & 3 & 6 & 3 & 2 & 2 & 1 \\
\hline$E$ & & & & 3 & & & 3 & 4 & 3 & 5 & 2 & 1 \\
\hline$F$ & & & & 1 & & & 3 & 4 & 3 & 3 & 2 & 1 \\
\hline $\begin{array}{c}\text { Production } \\
\text { lead time }\end{array}$ & 3 & 4 & 3 & 2 & 2 & 1 & & & & & & \\
\hline
\end{tabular}

Table 1. The transportation time distance between the nodes and the production lead times of example.

The input matrix and the generalised input matrix are thus given by:

$$
\mathbf{H}=\left[\begin{array}{llllll}
0 & 0 & 0 & 0 & 0 & 0 \\
1 & 0 & 0 & 0 & 0 & 0 \\
2 & 0 & 0 & 0 & 0 & 0 \\
0 & 3 & 0 & 0 & 0 & 0 \\
0 & 0 & 0 & 2 & 0 & 0 \\
0 & 0 & 0 & 1 & 0 & 0
\end{array}\right] ., \breve{H}(s)=\left[\begin{array}{cccccc}
0 & 0 & 0 & 0 & 0 & 0 \\
1 e^{7 s} & 0 & 0 & 0 & 0 & 0 \\
2 e^{6 s} & 0 & 0 & 0 & 0 & 0 \\
0 & 3 e^{6 s} & 0 & 0 & 0 & 0 \\
0 & 0 & 0 & 2 e^{5 s} & 0 & 0 \\
0 & 0 & 0 & 1 e^{3 s} & 0 & 0
\end{array}\right] .
$$

We assume that production is to take place in regular intervals of lengths $T_{i}=15,13,10,13$, 10,13 , and the first batch is to start at times $t_{i}=22,18,14,10,6,2$, respectively. The transform of production activities $\tilde{\mathbf{P}}(s)$ and the setup vector $\tilde{\mathbf{P}}^{\prime}(s)$ then become, cf [Grubbström 2007, Grubbström, Bogataj and Bogataj 2009]:

$$
\tilde{\mathbf{P}}(s)=\left[\begin{array}{c}
\vdots \\
\hat{P}_{i} e^{-s t_{i}} \\
1-e^{-s T_{i}} \\
\vdots
\end{array}\right], \tilde{\mathbf{P}}^{\prime}(s)=\left[\begin{array}{c}
\vdots \\
\frac{e^{-s t_{i}}}{1-e^{-s T_{i}}} \\
\vdots
\end{array}\right],
$$

where the $\hat{P}_{i}$ are constant batch sizes, assumed to have the values 100, 100, 200, 300, 600, 300 , respectively. The setup vector represents a sequence of unit impulses taking place at the same time as the production batches.

We are now in a position to evaluate the system according to the Net Present Value principle (NPV), provided that values of economic parameters in vector form concerning unit 
production prices/costs $\mathbf{p}$ and setup costs $\mathbf{K}$ and an interest rate $\rho$ are introduced (and interpreted as elements of the relevant cash flow). Let us assume the following values $\mathbf{p}=[560,38,25,34,14,15], \mathbf{K}=[5000,4500,5250,4875,4375,5375]$ and $\rho=0.065$. From the Net Present Value Theorem [Grubbström 1967] we then obtain the NPV of the cash flow involved as

$$
\mathrm{NPV}=\mathbf{p}(\mathbf{I}-\breve{\mathbf{H}}(\rho)) \tilde{\mathbf{P}}(\rho)-\mathbf{K} \tilde{\mathbf{P}}^{\prime}(\rho),
$$

where we have substituted the Laplace frequency s for the continuous interest rate $\rho$.

The costs of transportation are conveniently included in the relevant components of $\mathbf{p}$. For instance, we may examine the contribution from the production of $B$, which is

$$
\begin{aligned}
\mathrm{NPV} & =\mathbf{p}[\mathbf{I}-\breve{\mathbf{H}}(\rho)]_{\text {column } 2}\left[\frac{\hat{P}_{2} e^{-\rho t_{2}}}{1-e^{-\rho T_{2}}}\right]-[\mathbf{K}]_{\text {component } 2}\left[\frac{e^{-\rho t_{2}}}{1-e^{-\rho T_{2}}}\right]= \\
& =\left[38 \cdot 1-34 \cdot 3 \cdot e^{6 \cdot 0.065}\right]\left[\frac{100 \cdot e^{-18 \cdot 0.065}}{1-e^{-13 \cdot 0.065}}\right]-4500 \cdot\left[\frac{e^{-1880.065}}{1-e^{-130.065}}\right] .
\end{aligned}
$$

In this case, transportation of component $D$ entering $B$ begins 6 time units before completion before completion of $\mathrm{B}$, which is taken care of by the capitalisation factor $e^{6 \cdot 0.065}$. If included in the unit cost component of $\mathbf{p}$, .i. e. $p_{4}=34$, the transportation costs will be capitalised from the start of transportation until completion of $B$, and then discounted with the chain factor $e^{-18.0 .065} /\left(1-e^{-13 \cdot 0.065}\right)$. If revenues and costs are to be distributed over time in a more detailed fashion, the formula (15) needs to be modified. Such modifications have been dealt with concerning, for instance, capacity costs [Grubbström and Wang 2000, 2003, Huynh 2006].

With the numerical values assumed in this example, we obtain

$$
\begin{gathered}
\mathrm{NPV}=[560,38,25,34,14,15]\left[\begin{array}{cccccc}
1 & 0 & 0 & 0 & 0 & 0 \\
-e^{7 \rho} & 1 & 0 & 0 & 0 & 0 \\
-2 e^{6 \rho} & 0 & 1 & 0 & 0 & 0 \\
0 & -3 e^{6 \rho} & 0 & 1 & 0 & 0 \\
0 & 0 & 0 & -2 e^{5 \rho} & 1 & 0 \\
0 & 0 & 0 & -e^{3 \rho} & 0 & 1
\end{array}\right]\left[\begin{array}{r}
38.42 \\
54.41 \\
168.44 \\
274.55 \\
849.94 \\
461.80
\end{array}\right] \\
-[5000,4500,5250,4875,4375,5375]\left[\begin{array}{c}
0.384 \\
0.544 \\
0.842 \\
0.915 \\
1.417 \\
1.539
\end{array}\right]=26,976.65-27,723.8=-747.14 .
\end{gathered}
$$


This negative figure indicates that the production system is making a loss.

Of interest is to examine effects of saving times of transportation and production. Applying a sensitivity analysis to the time entries in $\breve{\mathbf{H}}(s)$ concerning transportation times with $\delta$, $0 \leq \delta \leq 1$, being a fraction of time saved, we then have:

$$
\breve{\mathbf{H}}(\rho)=\left[\begin{array}{cccccc}
1 & 0 & 0 & 0 & 0 & 0 \\
-e^{(3+4(1-\delta)) \rho} & 1 & 0 & 0 & 0 & 0 \\
-2 e^{(3+3(1-\delta)) \rho} & 0 & 1 & 0 & 0 & 0 \\
0 & -3 e^{(3+3(1-\delta)) \rho} & 0 & 1 & 0 & 0 \\
0 & 0 & 0 & -2 e^{(2+3(1-\delta)) \rho} & 1 & 0 \\
0 & 0 & 0 & -e^{(2+1(1-\delta)) 3 \rho} & 0 & 1
\end{array}\right] .
$$

Table 2 and Figure 5 show the influence that different values of $\delta$ will have on the total NPV.

\begin{tabular}{|l|r|}
\hline $\begin{array}{l}\text { Relative savings of } \\
\text { all transportation } \\
\text { times }(\delta)\end{array}$ & NPV \\
\hline 0 & -747.14 \\
\hline 0.10 & -289.53 \\
\hline 0.16421 & 0 \\
\hline 0.30 & 601.51 \\
\hline 0.50 & $1,461.29$ \\
1.00 & 3481.62 \\
\hline
\end{tabular}

Table 2: Economic consequences from reducing all transportation times.

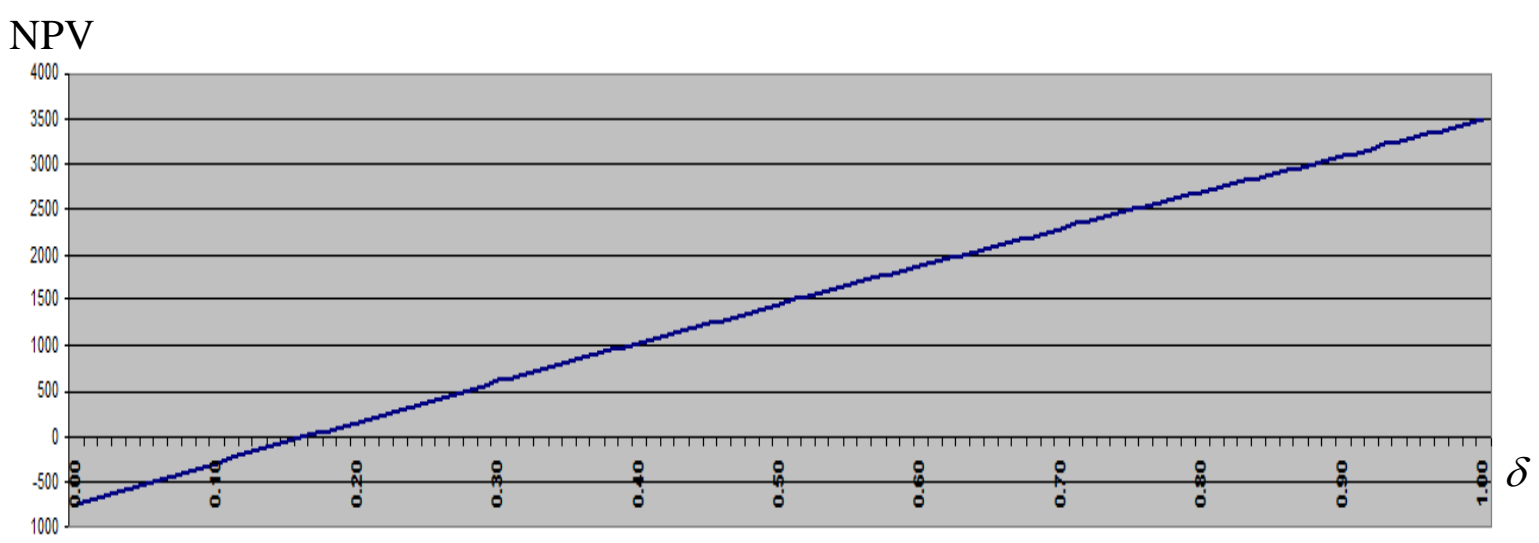

Figure 5. Effect on NPV from reducing all transportation times by a fraction $\delta$.

At a reduction level of $\delta$ around 16.5 per cent, the system starts making a profit. 
The effect would of course be drastically lowered if only an individual transportation time were considered. But that is also easy to model in a specific case. Figure 6 displays the individual effects from reducing a specific transportation time on the NPV as a whole for the five transportation times included.

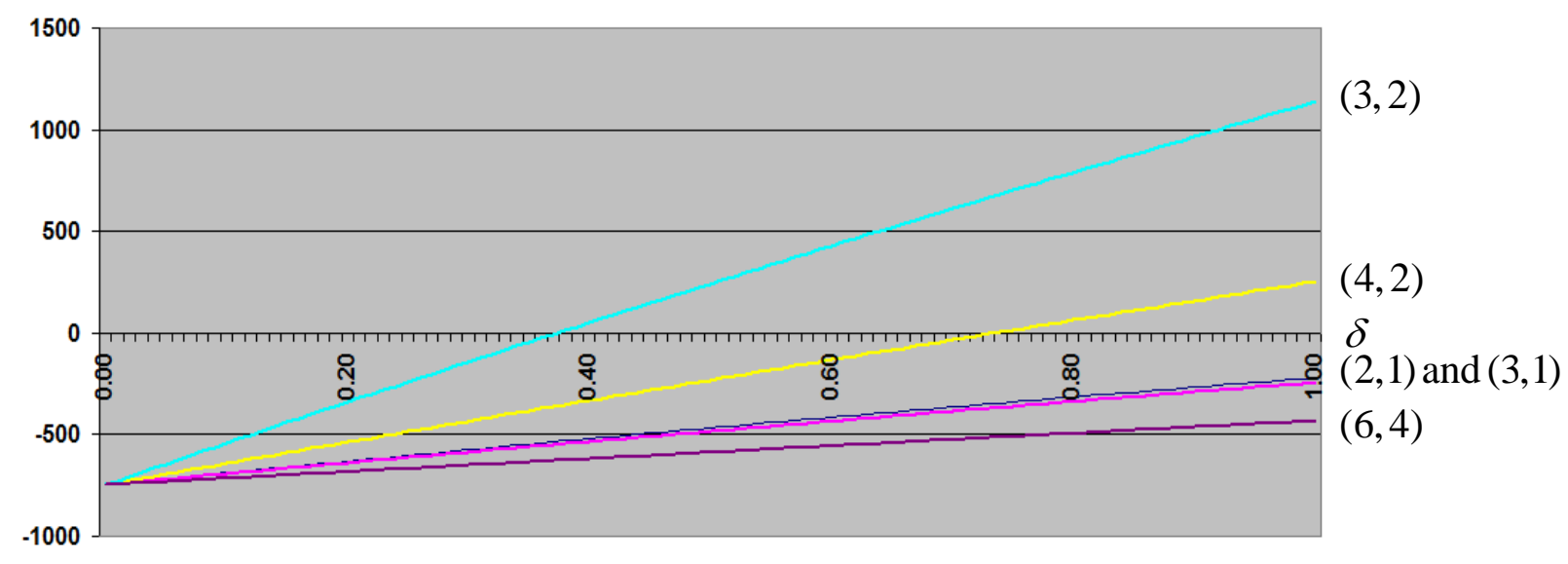

Figure 6. Effect on NPV from reducing individual transportation times by $\delta$. For instance, $(6,4)$ indicates reducing transportation time from $F$ to $D$.

Let us denote the slope of each line in Figure 6 by $b$ (origin,destination). If the company wishes to change the location of $\mathrm{D}$, then $\delta(6,4)$ and $\delta(4,2)$ will change. The company would then invest a certain maximum amount $\Delta C$ to accept this change, if this amount would be lower than the resulting change in the NPV of all activities in the supply chain, $\Delta C<b(6,4) \delta(6,4)-b(4,2) \delta(4,2)$.

\section{Conclusions}

In this paper we have made an attempt to extend the timing representation in MRP theory to a generalisation, by which inflow dependent times of activities (exemplified as transportation) may be covered. This has been made possible by extending the definition of the generalised technology matrix from $\tilde{\mathbf{G}}(s)-\tilde{\mathbf{H}}(s)$ to $\breve{\mathbf{G}}(s)-\breve{\mathbf{H}}(s)$, the latter which no longer may be written as the difference between the products $\tilde{\mathbf{G}}(s)=\tilde{\Delta}(s) \mathbf{G}$ and $\tilde{\mathbf{H}}(s)=\mathbf{H} \tilde{\boldsymbol{\tau}}(s)$. This provides us with an opportunity to study in a detailed way, for instance, the influence of transportation times varying in values for different product inputs to the same process. Details of systems in the closed loop value chain to which this might be applied can be found in [Grubbström, Bogataj and Bogataj 2007]. In general, we can conclude that the combination of Input-Output Analysis and Laplace transforms would provide a base for facilitating the analysis of a complete supply chain including the four sub-systems of manufacturing, distribution, consumption and reverse logistics.

The Net Present Value as a measure of economic performance can be used successfully to evaluate not only the production lead time, but also additional delays in the form of, for example, transportation times. These effects appear because of a nonzero interest rate and therefore a nonzero cost of capital, used in financing the flow of goods through the supply chain. It is also easy to distinguish the contributions to the NPV from different sources 
influencing the economic consequences. The numerical example in Section 4 provides such a case, in which is demonstrated the complete consequences due to transportation times. Adjusting the parameters representing the cause of delays enables us to derive explicit expressions for the consequences due to any type of delay.

Extensions to include capacity limitations would be a natural further development of theory.

\section{References}

Aseltine, J.A., 1958. Transform Method in Linear System Analysis, McGraw-Hill, New York, N.Y.

Bogataj, D., Bogataj, M., 2007. Measuring the supply chain risk and vulnerability in frequency space. International Journal of Production Economics, 108(1-2), 291-301.

Bogataj, M., 1999. Inventory allocation and customer travelling problem in spatial duopoly. International Journal of Production Economics, 59, 271-279.

Bogataj, M., Bogataj, L., 2003. On the compact presentation of the lead time perturbations in distribution networks, International Journal of Production Economics, 88(2), 145-155.

Bogataj, M., Bogataj, L., 2001. Supply chain coordination in spatial games. International Journal of Production Economics, 71, 277-286.

Bogataj, M., Grubbström, R. W., Bogataj, L., 2009. MRP-DRP model as a base for negotiations in times of recession. In: Balci, O. (Ed.). MAS 2009. La Laguna: ISAATC, Universidad, 155-162.

Dellaert, N.,. Jeunet, J., 2000. Solving large unconstrained multilevel lot-sizing problems using a hybrid genetic algorithm, International Journal of Production Research, 38(5), 1083 - 1099.

Dellaert, N., Jeunet, J., Jonard, N., 2000. A genetic algorithm to solve the general multi-level lot-sizing problem with time-varying costs, International Journal of Production Economics, 68, 241 - 257.

Ferrer, G., Whybark, C., 2000. Material Planning for a Remanufacturing Facility. In: Machuca, J. A. D., Mandakovic, T., (Eds). POM - Facing the New Millenium, Production and Operations Management Society and the University of Sevilla, Sevilla, 225-236.

Grubbström, R. W., 1967. On the Application of the Laplace Transform to Certain Economic Problems, Management Science, 13(7), 558-567.

Grubbström, R. W., 1996. Stochastic Properties of a Production-Inventory Process With Planned Production Using Transform Methodology, International Journal of Production Economics, 45, 407-419.

Grubbström, R. W., 1997. Ekonomisk teori (Economic Theory), in Swedish, Academia Adacta, Bjärred.

Grubbström, R. W., 2007. Transform Methodology Applied to Some Inventory Problems, Zeitschrift für Betriebswirtschaft, 77(3), 297-324.

Grubbström, R. W., 2008. Reverse Logistics - On methodology for modelling remanufacturing production-inventory systems, Keynote Opening Address, II International Conference in Industrial Engineering, Burgos, Spain, September 3-5.

Grubbström, R. W., 2009. Extensions of MRP Theory with Application to Distribution and Remanufacturing, Keynote Opening Address, Proceedings, Second International Workshop on Successful Strategies in Supply Chain Management, Hong Kong, January 8-9, 3-19.

Grubbström, R. W., Bogataj, L., Bogataj, M., 2007. A Compact Representation and Optimisation of Distribution and Reverse Logistics in the Value Chain, WP, (Mathematical economics, operational research and logistics, 5), Ljubljana: Faculty of Economics, KMOR, Slovenia. 
Grubbström, R. W., Bogataj, M., Bogataj, L., 2009. Optimal Lotsizing within MRP Theory, Annual Reviews in Control, 34(1), 2010, 89-100.

Grubbström, R. W., Ovrin, P., 1992. Intertemporal Generalization of the Relationship between Material Requirements Planning and Input-Output Analysis, International Journal of Production Economics, 26(1-3), 311-318.

Grubbström, R. W., Tang, O., 2000. An Overview of Input-Output Analysis Applied to Production-Inventory Systems, Economic Systems Review, 12, 3-25.

Grubbström, R. W., Tang, O., 2011. The space of solution alternatives in the optimal lotsizing problem for general assembly systems applying MRP theory, International Journal of Production Economics. In Press, doi:10.1016/j.ijpe.2011.01.012.

Grubbström, R. W., Wang, Z., 2000. Introducing Capacity Limitations into Multi-Level, Multi-Stage Production-Inventory Systems Applying the Input Output/Laplace Transform Approach, International Journal of Production Research, 38(17), 4227-4234.

Grubbström, R. W., Wang, Z., 2003. A Stochastic Model of Multi-Level/Multi-Stage Capacity-Constrained Production-Inventory Systems, International Journal of Production Economics, 81-82, 483-494.

Huynh, T. T. T., 2006. Capacity Constraints in Multi-Stage Production-Inventory Systems Applying Material Requirements Planning Theory, Production-Economic Research in Linköping, PROFIL 23, Linköping.

Kaku, I., Li, Z., Xu, C., 2009. A Simple Heuristic Algorithm Based on Segmentation to Solve Multilevel Lot-sizing Problems, Preprints of the 13th IFAC Symposium on Information Control Problems in Manufacturing, Moscow, Russia, June 3-5, 550-555.

Kim, J-U., Kim, Y-D., 1996. Simulated Annealing and Genetic Algorithms for Scheduling Products with Multi-level Product Structure, Computers \& Operations Research, 23, 857868.

Kimms, A., 1999. A Genetic Algorithm for Multi-level, Multi-machine Lot Sizing and Scheduling, Computers \& Operations Research, 26, 829-848.

Koopmans, T. C., (Ed.), 1951. Activity Analysis of Production and Allocation, Wiley, New York, N.Y.

Kuik, R., Salomon, M., 1990. Multi-level Lot-sizing Problem: Evaluation of a Simulated Annealing Heuristic, European Journal of Operational Research, 45, 25-37.

Lancaster, K. B., 1968. Mathematical Economics, New York.

Leontief, W. W., 1928. Die Wirtschaft als Kreislauf, Archiv für Sozialwissenschaft und Sozialpolitik, 60, 577-623.

Leontief, W. W., 1951. The Structure of the American Economy, Oxford University Press, London.

Rosen, K. H., 1988. Discrete Mathematics and its Applications, AT\&T Information Systems Inc., Distributed by McGraw Hill, New York.

Segerstedt, A., 1996. A Capacity-Constrained Multi-level Inventory and Production Control Problem, International Journal of Production Economics, 45, 449-461.

Tang, O., 2004. Simulated annealing in lot sizing problems, International Journal of Production Economics, 88, 173-181.

Vazsonyi, A., 1955. The Use of Mathematics in Production and Inventory Control, Management Science, 1(1), 70-85.

Vazsonyi, A., 1958. Scientific Programming in Business and Industry, Wiley, New York, N.Y. 